\title{
Automatic Generation of Programs for Data Tables with Batch Least Square Mamdani Inference Systems: Application in the AWG Table
}

\author{
Martín Montes Rivera ${ }^{1}$, Alberto Ochoa Zezzatti ${ }^{2}$, Christian Alejandro Mejía Ramírez ${ }^{1}$ \\ ${ }^{1}$ Universidad Politécnica de Aguascalientes, Mexico \\ ${ }^{2}$ Universidad Juárez Autónoma de Tabasco, Mexico \\ martin.montes@upa.edu.mx, alberto.ochoa@uacj.mx
}

\begin{abstract}
Tables are used in several areas where is required to show value responses, relationships, scores, percentages, and statistical results, among others. Tables increase accessing speed to information, but they need space for be presented and saving space could make that all the required values be not always included. Computer programs can replace tables, so that space not be required when presenting information, this has been explored since computers were developed presenting several algorithms. Fuzzy systems could be an alternative to generate programs for replace tables, more over this allow to get an expert system that knows the data in the table, but fuzzy systems require several numerical parameters to be tuned. In this paper is proposed the use of Batch Least Square Mamdani system for mimic tables in computer programs specifically applied in the AWG table which is a very common table used by engineers and electrical technicians.
\end{abstract}

Keywords: tables to programs, system identification, batch least square Mamdani systems.

\section{Introduction}

Arrays of rows and columns for presenting information are called tables, they are used in several areas where is required to show value responses, relationships, scores, percentages, and statistical results, among others. Measurements obtained from input-output models and the evaluation of functions are information that could be also expressed using tables by describing the behavior of dependent variables in function of independent variables; i.e., its relation can be expressed as a mathematical function [1].

Tables increase the speed when accessing to information, but they need space so that tables be presented and this could make that all the required values be not always included forcing a person to perform interpolation or extrapolation operations for determining the missing values [1].

Computer programs can replace tables, especially when it is possible to stablish specific ranges for determining values in tables. More over this have been documented since computers were developed leading to the creation of specific algorithms like those proposed in [2]. 
An alternative way for converting tables to programs is explored in [1] in this work tables are returned to equations by using Genetic Programming (GP) an optimizing algorithm for determining unknown structures using natural selection principles. But this technique uses a high complexity algorithm, which could demand long time for determining a suitable equation solution, depending from the data.

Fuzzy inference systems are based on Zadeh proposed fuzzy logic, which is the same kind of logic used when constructing inference rules, i.e. if then rules, but with fuzzy limits in range [0,1] or not binary concluding limits (crisp logic) [3].

Fuzzy systems are based on expert knowledge which is knowledge given by an expert, i.e., the input data for training them is given as correct and then systems are heuristically trained for following the intrinsic logic in the input data allowing them to be applied in several areas like modeling human reasoning, recommendation systems, systems identification, automatic control among others [4].

Input data for training inference systems it is always in pairs because its required a relational input-output map containing the expert knowledge, since the system must react correctly for an input premise with an output consequence (If input is $\mathrm{A}$ then output is B) [3].

When fuzzy systems are correctly trained they become an available expert to assist persons selecting the correct resource or action depending from the application, in this case use the AWG gauge table would generate a system that automatically recommend the best wire for a specific application.

Inference systems are always trained using numerical data (expert knowledge) like the information in a table for example in the AWG table (Table 1) there are several columns that describe information for 33 kinds of wires with different proprieties. If the AWG table is adjusted as input data for training an inference system, this would require a single input for the AWG gauge and 9 outputs for giving the 9 columns information about every specific class of wire (Fig. 1), when this is manually adjusted fuzzy sets are tuned by setting its numerical parameters, supposing that there are 3 fuzzy sets per input and output with 3 parameters each one, then would be at least 30 numerical parameters that must be adjusted and this does not guarantee that all the data in the table would be correctly reproduced [5].

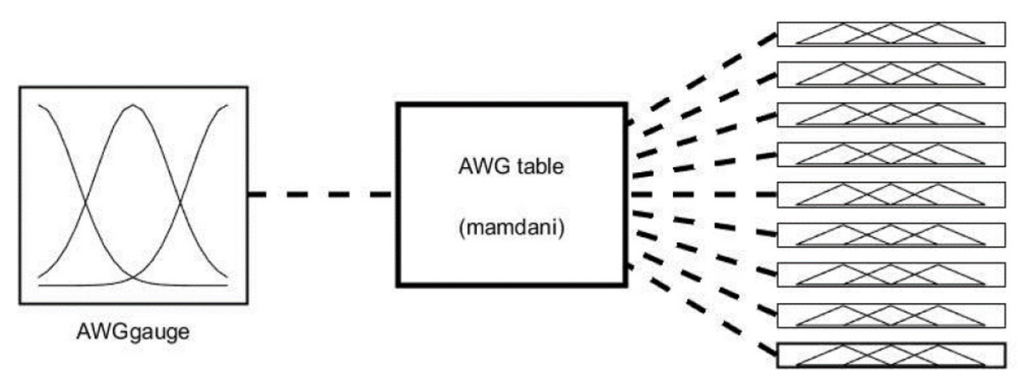

Fig. 1. Inference system required for mimic AWG table.

To reduce the complexity of the system for tuning the parameters the fuzzy system could be divided into 9 sub-systems with a single input and a single output (Fig. 2) and 
there would be 6 numerical parameters per sub-system that must be optimized, but this would require 54 total numerical parameters to be adjusted.
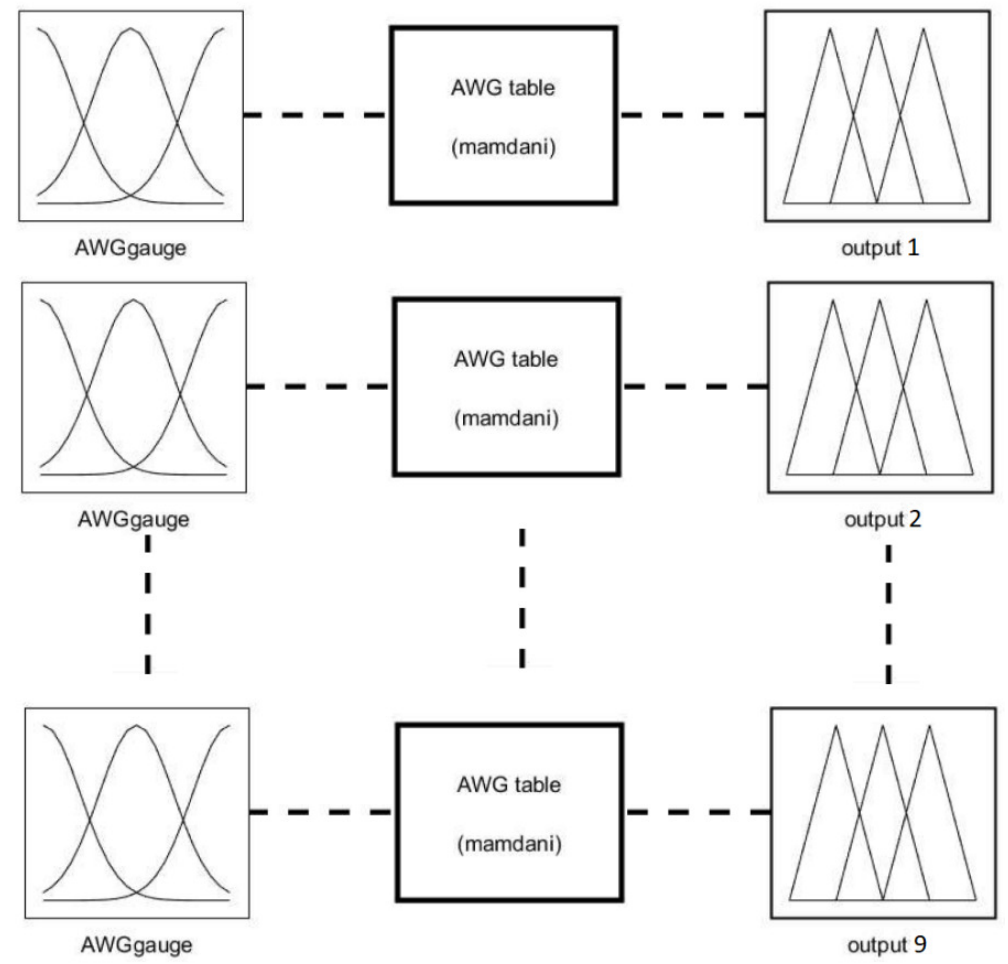

Fig. 2. Divided Inference System for AWG table.

There is an alternative that can compute the required fuzzy sets and its numerical parameters for the AWG table. The Batch Least Square Mamdani (LSM) is a technique used in fuzzy control and system identification that can automatically tune an inference system by calculating the inverse of its input parameters the same way that it is done in the Least Square Estimator (LSE).

Fuzzy inference systems have been spread in several areas since its very beginning in 1965, today there still appearing several applications because of its capability for mimic human reasoning using expert knowledge. There are several papers where fuzzy systems have been applied in the recent years, they have been used in image enhancement in [6], image compression analysis in [7], risk evaluation and periodization in industries in [8], estimating the length-weight relationship of fishes in [9], for failure analyzing in automobile industry in [10], in the assessment of power transformers in [11], among other several applications.

In this paper it is proposed the use of LSM for mimic tables in computer programs specifically applied in the AWG table and the user can select an acceptable error in the operation so that the system complexity be related with this error. 
Table 1. AWG gauge table [5].

\begin{tabular}{|c|c|c|c|c|c|c|c|c|c|}
\hline $\begin{array}{l}\text { AWG } \\
\text { gauge }\end{array}$ & $\begin{array}{l}\text { Conduc- } \\
\text { tor Di- } \\
\text { ameter } \\
\text { (in) }\end{array}$ & $\begin{array}{c}\text { Con- } \\
\text { ductor } \\
\text { Diame- } \\
\text { ter } \\
(\mathrm{mm})\end{array}$ & $\begin{array}{l}\text { Conduc- } \\
\text { tor cross } \\
\text { section } \\
\text { in } \mathrm{mm}^{2}\end{array}$ & $\begin{array}{l}\text { Ohms } \\
\text { per } \\
1000 \\
\text { ft. }\end{array}$ & $\begin{array}{l}\text { Ohms } \\
\text { per km }\end{array}$ & $\begin{array}{l}\text { Max. } \\
\text { Amps } \\
\text { for } \\
\text { chassis } \\
\text { wiring }\end{array}$ & $\begin{array}{l}\text { Max. } \\
\text { Amps } \\
\text { for } \\
\text { power } \\
\text { trans- } \\
\text { mission }\end{array}$ & $\begin{array}{c}\text { Maximum } \\
\text { frequency } \\
\text { for } 100 \% \\
\text { skin depth } \\
\text { for solid } \\
\text { conductor } \\
\text { copper }\end{array}$ & $\begin{array}{c}\text { Breaking } \\
\text { force } \\
\text { soft an- } \\
\text { nealed } \\
\mathrm{Cu} \\
37000 \\
\text { PSI } \\
(\mathrm{lbs}) \\
\end{array}$ \\
\hline 0 & 0.3249 & 8.2525 & 53.5 & 0.0983 & 0.322424 & 245 & 150 & $250 \mathrm{~Hz}$ & 3060 \\
\hline 1 & 0.2893 & 7.3482 & 42.4 & 0.1239 & 0.406392 & 211 & 119 & $325 \mathrm{~Hz}$ & 2430 \\
\hline 2 & 0.2576 & 6.5430 & 33.6 & 0.1563 & 0.512664 & 181 & 94 & $410 \mathrm{~Hz}$ & 1930 \\
\hline 3 & 0.2294 & 5.8268 & 26.7 & 0.197 & 0.64616 & 158 & 75 & $500 \mathrm{~Hz}$ & 1530 \\
\hline 4 & 0.2043 & 5.1892 & 21.1 & 0.2485 & 0.81508 & 135 & 60 & $650 \mathrm{~Hz}$ & 1210 \\
\hline 5 & 0.1819 & 4.6203 & 16.8 & 0.3133 & 1.02436 & 118 & 47 & $810 \mathrm{~Hz}$ & 960 \\
\hline 6 & 0.162 & 4.1148 & 13.3 & 0.3951 & 1.29393 & 101 & 37 & $1100 \mathrm{~Hz}$ & 760 \\
\hline 7 & 0.1443 & 3.6652 & 10.6 & 0.4982 & 1.63898 & 89 & 30 & $1300 \mathrm{~Hz}$ & 605 \\
\hline 8 & 0.1285 & 3.2639 & 8.37 & 0.6282 & 2.05607 & 73 & 24 & $1650 \mathrm{~Hz}$ & 480 \\
\hline 9 & 0.1144 & 2.9058 & 6.63 & 0.7921 & 2.59567 & 64 & 19 & $2050 \mathrm{~Hz}$ & 380 \\
\hline 10 & 0.1019 & 2.5883 & 5.26 & 0.9989 & 3.2772 & 55 & 15 & $2600 \mathrm{~Hz}$ & 314 \\
\hline 11 & 0.0907 & 2.3038 & 4.17 & 1.26 & 4.1339 & 47 & 12 & $3200 \mathrm{~Hz}$ & 249 \\
\hline 12 & 0.0808 & 2.0523 & 3.31 & 1.588 & 5.21 & 41 & 9.3 & $4150 \mathrm{~Hz}$ & 197 \\
\hline 13 & 0.072 & 1.8288 & 2.63 & 2.003 & 6.572 & 35 & 7.4 & $5300 \mathrm{~Hz}$ & 150 \\
\hline 14 & 0.0641 & 1.6281 & 2.08 & 2.525 & 8.284 & 32 & 5.9 & $6700 \mathrm{~Hz}$ & 119 \\
\hline 15 & 0.0571 & 1.4503 & 1.65 & 3.184 & 10.45 & 28 & 4.7 & $8250 \mathrm{~Hz}$ & 94 \\
\hline 16 & 0.0508 & 1.2903 & 1.31 & 4.016 & 13.18 & 22 & 3.7 & $11 \mathrm{k} \mathrm{Hz}$ & 75 \\
\hline 17 & 0.0453 & 1.1506 & 1.04 & 5.064 & 16.614 & 19 & 2.9 & $13 \mathrm{k} \mathrm{Hz}$ & 59 \\
\hline 18 & 0.0403 & 1.0236 & 0.823 & 6.385 & 20.948 & 16 & 2.3 & $17 \mathrm{kHz}$ & 47 \\
\hline 19 & 0.0359 & 0.91186 & 0.653 & 8.051 & 26.414 & 14 & 1.8 & $21 \mathrm{kHz}$ & 37 \\
\hline 20 & 0.032 & 0.8128 & 0.519 & 10.15 & 33.301 & 11 & 1.5 & $27 \mathrm{kHz}$ & 29 \\
\hline 21 & 0.0285 & 0.7239 & 0.412 & 12.8 & 41.995 & 9 & 1.2 & $33 \mathrm{kHz}$ & 23 \\
\hline 22 & 0.0253 & 0.64516 & 0.327 & 16.14 & 52.953 & 7 & 0.92 & $42 \mathrm{kHz}$ & 18 \\
\hline 23 & 0.0226 & 0.57404 & 0.259 & 20.36 & 66.798 & 4.7 & 0.729 & $53 \mathrm{kHz}$ & 14.5 \\
\hline 24 & 0.0201 & 0.51054 & 0.205 & 25.67 & 84.219 & 3.5 & 0.577 & $68 \mathrm{kHz}$ & 11.5 \\
\hline 25 & 0.0179 & 0.45466 & 0.162 & 32.37 & 106.201 & 2.7 & 0.457 & $85 \mathrm{kHz}$ & 9 \\
\hline 26 & 0.0159 & 0.40386 & 0.128 & 40.81 & 133.891 & 2.2 & 0.361 & $107 \mathrm{kHz}$ & 7.2 \\
\hline 27 & 0.0142 & 0.36068 & 0.102 & 51.47 & 168.865 & 1.7 & 0.288 & $130 \mathrm{kHz}$ & 5.5 \\
\hline 28 & 0.0126 & 0.32004 & 0.080 & 64.9 & 212.927 & 1.4 & 0.226 & $170 \mathrm{kHz}$ & 4.5 \\
\hline 29 & 0.0113 & 0.28702 & 0.0647 & 81.83 & 268.471 & 1.2 & 0.182 & $210 \mathrm{kHz}$ & 3.6 \\
\hline 30 & 0.01 & 0.254 & 0.0507 & 103.2 & 338.583 & 0.86 & 0.142 & $270 \mathrm{kHz}$ & 2.75 \\
\hline 31 & 0.0089 & 0.22606 & 0.0401 & 130.1 & 426.837 & 0.7 & 0.113 & $340 \mathrm{kHz}$ & 2.25 \\
\hline 32 & 0.008 & 0.2032 & 0.0324 & 164.1 & 538.386 & 0.53 & 0.091 & $430 \mathrm{kHz}$ & 1.8 \\
\hline
\end{tabular}

\section{Theoretical Framework}

Fuzzy inference systems describe systems that reason using inference rules i.e. IFTHEN rules, and its general structure is given in Fig. 3. 
Automatic Generation of Programs for Data Tables with Batch Least Square Mamdani Inference...

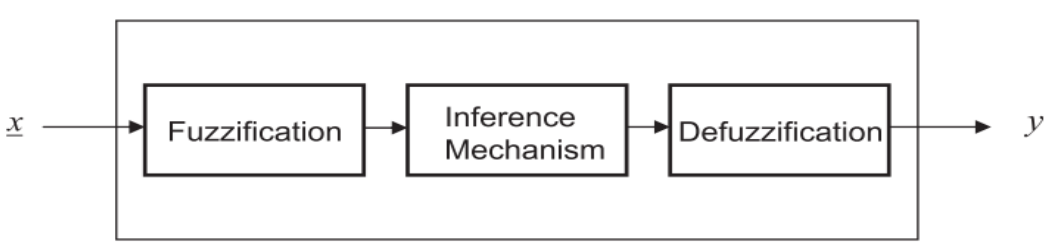

Fig. 3. General structure of fuzzy systems [3].

Fuzzification is the part where a scalar input data is transformed to fuzzy data by identifying its corresponding membership value $(\mu)$ in range $[0,1]$ for the input sets. Fuzzy input sets are obtained using mathematical functions called membership functions, which determine the membership grade for a certain premise with the input data, for example in the LSM Gaussian membership functions are used with equation (1), corresponding with the shape shown in Fig. 4 [3]:

$$
\mu(x)=e^{-\frac{1}{2}\left(\frac{x-c}{\sigma}\right)^{2}} .
$$

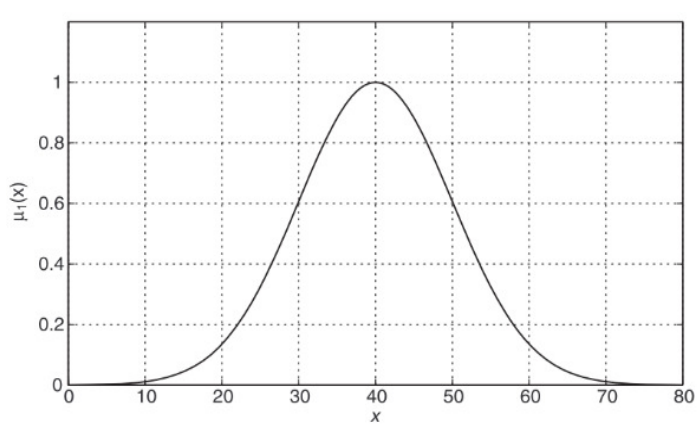

Fig. 4. Gaussian membership function.

The Gaussian membership function require 2 numerical parameters that must be selected for adjusting the fuzzy set according to given problem, the parameter $c$ variates the function center while the parameter $\sigma$ variates its spread [3].

Mamdani fuzzy inference system connects al premises using max and min operations related to OR and AND connectors, these operations are performed with the membership values of the fuzzy sets [3].

Mamdani fuzzy inference system conclude using as mechanism of inference min operation between the input sets and the output sets according to equation (2):

$$
\min \left(\mu_{i}(x), \mu_{o}(y)\right),
$$

where $\mu_{i}(x)$ is the membership of the input set with $x \in X$ the input universe and $\mu_{i}(y)$ is the membership of the output set with $y \in Y$ the output universe, depending from the number of inputs and outputs it is possible to have more than one input and output in their respective universes. 
Defuzzification of Mamdani inference system is performed with Center of Gravity (COG), which is performed according to equation (3):

$$
y=\frac{\sum_{i=1}^{n} y \cdot \mu(y)}{\sum_{i=1}^{n} \mu(\mathrm{y})},
$$

where $\mathrm{n}$ is the number of output elements in the output set, determined with the aggregation operation which in Mamdani systems is the max operation.

Least square estimation finds the parameters that minimize the square difference between estimated and obtained parameters but applied to an inference system there could be expressed as the contribution of the input sets to the output sets, equation (4):

$$
y(j)=\phi_{1}(j) \theta_{1}+\phi_{2}(j) \theta_{2}+\phi_{3}(j) \theta_{3}+\ldots+\phi_{R}(j) \theta_{R},
$$

where $\phi_{R}$ are the $R$ parameters known corresponding to fuzzy sets and $\theta_{R}$ are the $R$ constant parameters unknown that are adjusted for guarantee a desired response so if the system can be written as

$$
y(j)=\Phi^{T}(j) \Theta,
$$

with $\Theta$ containing al the unknown $\theta$ constant parameters that optimize the fuzzy inference system for its desired response.

But with Batch Least Square can be computed like described in [3] with equation (6):

$$
\Theta=\left(\Phi^{T} \Phi\right)^{-1} \Phi^{T} Y,
$$

where $Y$ contain all the desired responses or values in a table for the proposed application in this work.

Following Mamdani inference systems defuzzification can be obtained with equation (3), but if all parameters are separated before summing its numerator with the same denominator then a new expression can be generalized as in equation (7):

$$
\xi_{i}(x)=\frac{\mu_{i}(x)}{\sum_{i=1}^{R} \mu_{i}(x)},
$$

where $\xi_{i}$ is the fuzzy basis function of the $i$ rule like described in [3], so $\Phi^{T}=\left[\xi_{1}(\mathrm{x}) \ldots \xi_{R}(\mathrm{x})\right]$ and then will compute the desired system by obtaining the $\Theta$ parameters [3].

\section{Methodology}

The AWG table is separated in fuzzy systems like in Fig. 2 then every fuzzy system is trained using the LSM formulation where $\Theta$ parameters are determined and the number of required parameters for satisfying a specific desired error in the generation of the program. 
Automatic Generation of Programs for Data Tables with Batch Least Square Mamdani Inference...

After that table and systems are separated then the desired values for the output systems are assigned to $Y$ for a given column like in equation (8), with $i$ describing de corresponding column and system:

$$
Y_{i}=c_{i}
$$

Then all systems compute the $\Phi_{i}{ }^{T}$ matrix using equation (7) and the constant parameters required for mimic the columns in the AWG table using equation (6).

To modify the complexity of the system i.e. the quantity of required input fuzzy sets the new output response is calculated with equation (5) and then relative error is calculated with equation (9):

$$
e=\frac{\hat{Y}-Y}{Y},
$$

where $\hat{Y}$ is the obtained response with the Mamdani fuzzy system adjusted with LSM.

The system complexity it is initialized in 1and then is increased until $e<e_{d}$ with $e_{d}$ given as the desired error.

\section{$4 \quad$ Results}

In this section are presented the results obtained after use LSM for determining every fuzzy system related to its corresponding column so that the union of all 9 fuzzy systems replace the AWG table.

The AWG table can be extended to more values but in this program was used with the 33 different wires shown in the Table 1 . The obtained $\Theta_{i}$ matrixes with the coefficients for each fuzzy set in the $i$ system are shown in equations 10 to 18 , all of then satisfying $e<0.01$ i.e. a relative error of $1 \%$.

$$
\begin{gathered}
\Theta_{1}=[0.3330,0.2531,0.2039,0.1605,0.1278,0.1011,0.0803,0.0637 \\
0.0505,0.0400,0.0318,0.0251,0.0200,0.0158,0.0125,0.0100,0.0077] \\
\Theta_{2}=[8.4579,6.4276,5.1797,4.0775,3.2459,2.5688,2.0390,1.6177 \\
1.2822,1.0171,0.8070,0.6410,0.5072,0.4015,0.3186,0.2536,0.1964] \\
\Theta_{3}=[55.8069,31.6841,20.9408,12.8395,8.2121,5.0898,3.2347,2.0220 \\
1.2767,0.8010,0.5052,0.3186,0.1994,0.1246,0.0784,0.0499,0.0299] \\
\Theta_{4}=[0.0912,0.1532,0.2415,0.3847,0.6114,0.9723,1.5467,2.4565,3.9121, \\
6.2076,9.9024,15.6516,25.1509,39.2994,64.3206,97.2561,171.1798] \\
\Theta_{5}=[0.2989,0.5034,0.7900,1.2624,2.0032,3.1890,5.0750,8.0596,12.8403 \\
20.3640,32.4893,51.3503,82.5162,128.9349,211.0261,319.0815,561.6136]^{\prime} \\
\Theta_{6}=[252.1789,193.0706,159.1440,128.1148,103.1033,84.9516,64.1592,54.0400,42.3556,34.3010 \\
30.8227,21.5508,17.5140,14.1156,10.0950,7.4230,4.0581,2.8224,2.1002,1.4242,1.1967,0.7189,0.5163]^{\prime}
\end{gathered}
$$


The structures variates per column according to the number of Gaussians required per inference machine, as shown in table 2.

Table 2. Fuzzy structure characteristics after adapting to AWG table.

\begin{tabular}{|c|c|c|c|c|}
\hline $\begin{array}{c}\text { Name of column } \\
\text { in table }\end{array}$ & $\begin{array}{c}\text { Number of } \\
\text { Gaussian } \\
\text { functions }\end{array}$ & Desired Error & $\begin{array}{c}\text { Ob- } \\
\text { tained } \\
\text { Error }\end{array}$ & $\begin{array}{c}\text { Computing } \\
\text { time (sec- } \\
\text { onds) }\end{array}$ \\
\hline $\begin{array}{c}\text { Conductor Diameter } \\
\text { (in) }\end{array}$ & 17 & $1 \%$ & $0.1 \%$ & 0.084453 \\
\hline $\begin{array}{c}\text { Conductor Diameter } \\
\text { (mm) }\end{array}$ & 17 & $1 \%$ & $0.1 \%$ & 0.078887 \\
\hline $\begin{array}{c}\text { Conductor cross sec- } \\
\text { tion in mm } \text { m }^{2}\end{array}$ & 17 & $1 \%$ & $0.5 \%$ & 0.073799 \\
\hline Ohms per 1000 ft. & 17 & $1 \%$ & $0.5 \%$ & 0.075804 \\
\hline Ohms per km & 17 & $1 \%$ & $0.5 \%$ & 0.081492 \\
\hline $\begin{array}{c}\text { Max. Amps for chas- } \\
\text { sis wiring }\end{array}$ & 23 & $1 \%$ & $0.7 \%$ & 0.170864 \\
\hline $\begin{array}{c}\text { Max. Amps for } \\
\text { power transmission }\end{array}$ & 17 & $1 \%$ & $0.9 \%$ & 0.202492 \\
\hline $\begin{array}{c}\text { Maximum frequency } \\
\text { for 100\% skin depth } \\
\text { for solid conductor } \\
\text { copper }\end{array}$ & 25 & $0.9 \%$ & 0.077608 \\
\hline $\begin{array}{c}\text { Breaking force soft } \\
\text { annealed Cu 37000 } \\
\text { PSI }\end{array}$ & 17 & $1 \% 44$ \\
\hline
\end{tabular}

Figures 5 to 13 show the comparison between the plot of real data in the AWG table and the obtained using the fuzzy system trained with LSM and the obtained matrixes $A_{1 \ldots 9}$.

The results were computed in a maximum time of 0.277147 seconds for the column Maximum amps for power transmission (A) for AWG gauge and in a minimum time of 0.095222 seconds for the column Conductor diameter $(\mathrm{mm})$ for AWG gauge. 
Automatic Generation of Programs for Data Tables with Batch Least Square Mamdani Inference...

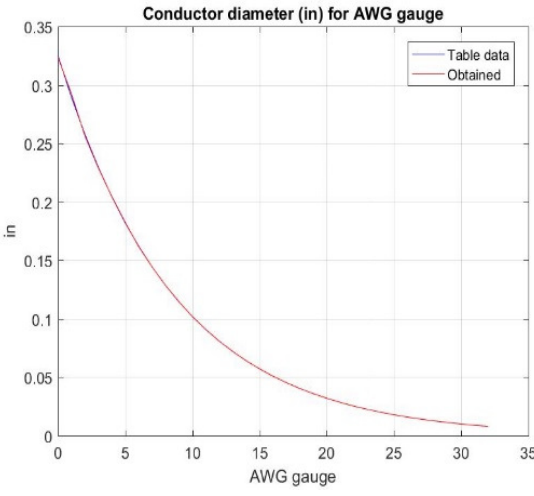

Fig. 5. Fuzzy system vs table column 1 .

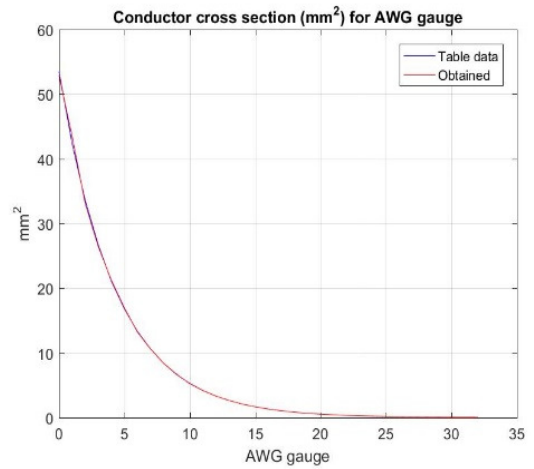

Fig. 7. Fuzzy system vs table column 3.

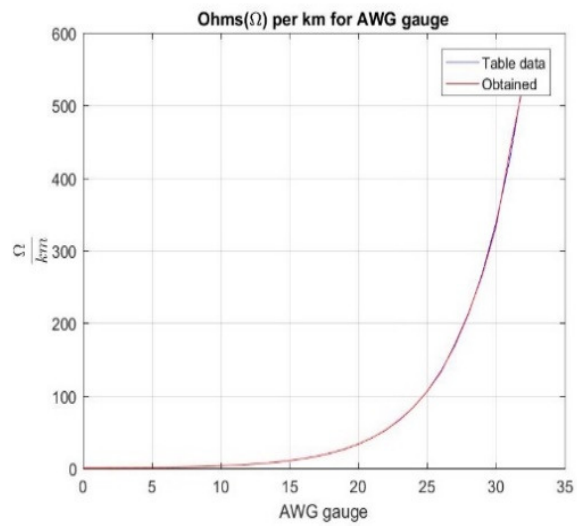

Fig. 9. Fuzzy system vs table column 5.

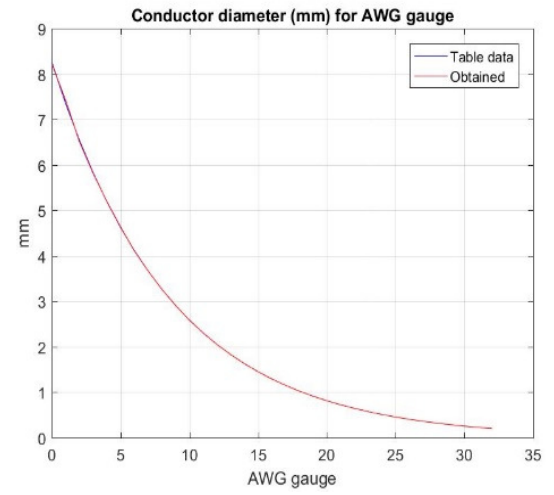

Fig. 6. Fuzzy system vs table column 2 .

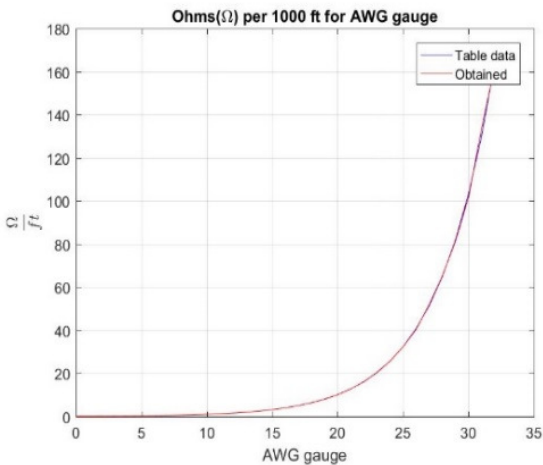

Fig. 8. Fuzzy system vs table column 4 .

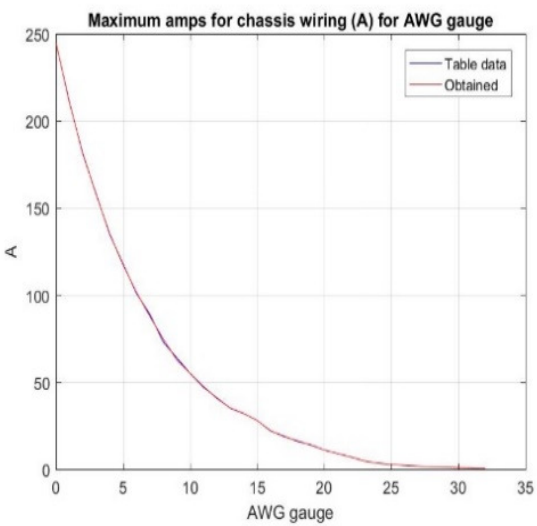

Fig. 10. Fuzzy system vs table column 6 . 


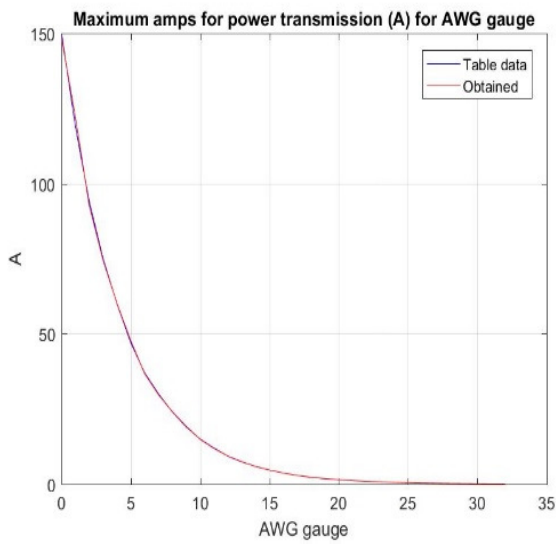

Fig. 11. Fuzzy system vs table column 7.

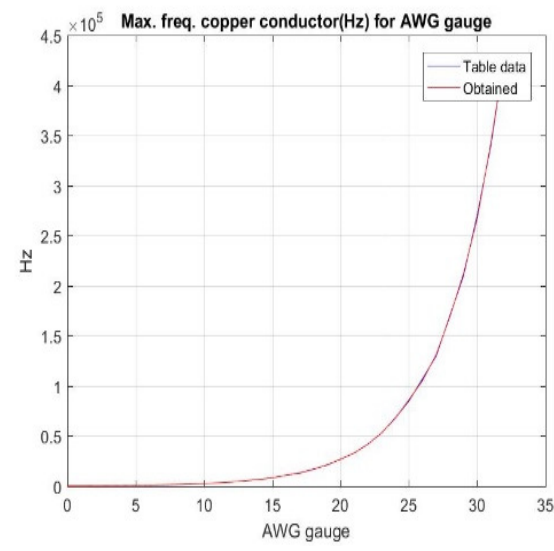

Fig. 12. Fuzzy system vs table column 8 .

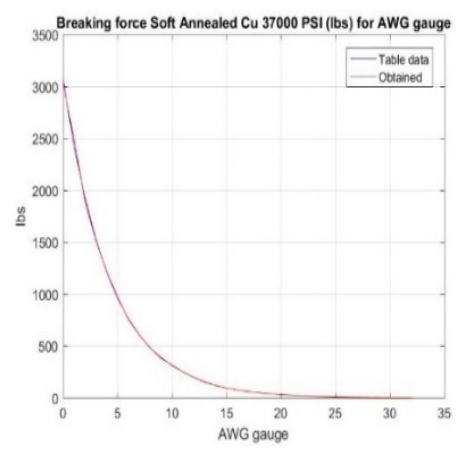

Fig. 13. Fuzzy system vs table column 9.

\section{Conclusions}

In this paper is presented an alternative to generate programs automatically from huge tables using Batch Least Square Mamdani Inference Systems with the desired error specifically applied in the AWG table, where time required for computing is less than 0.202492 seconds per column in tables, depending mainly from the spent time in the inverse equation (6). These results are achieved with a relative error minor than $1 \%$.

\section{References}

1. Montes Rivera, M., Aguilar Justo, M.O., Ochoa Zezzatti, A.: (2016). Equations for Describing Behavior Tables in Thermodynamics Using Genetic Programming: Synthesizing the Saturated Water and Steam Table. Research in Computing Science 122, 9-23 (2016) 
Automatic Generation of Programs for Data Tables with Batch Least Square Mamdani Inference...

2. Pollack, S.L.: Conversion of Limitedl-Entry Decision Tables to Computer Programs. Comunications of the ACM, 677-682 (1965)

3. Lilly, J.H.: Fuzzy Control and Identification. Hoboken, New Jersey: John Wiley \& Sons (2010)

4. Passino, K.M.: Fuzzy Control. Menlo Park, California: Addison-Wesley (1998)

5. Lund Instrument Engineering: Power Stream . Retrieved from Wire Gauge and Current Limits Including Skin Depth and Strength: http://www.powerstream.com/Wire_Size.htm (2018)

6. Chithrakshi, T.H.: Image Compression Using Fuzzy Enhancement. International Journal of Engineering and Advanced Technology, 348-351 (2014)

7. Kumar Gangwar, R., Kumar, M., Jaiswal, A., Saxena, R.: Performance Analysis of Image Compression Using Fuzzy Logic Algorithm. Signal \& Image Processing: An International Journal, 73-80 (2014)

8. Wen Kerk, Y., Meng Tay, K., Peng Lim, C.: An Analytical Interval Fuzzy Inference System for Risk Evaluation and Prioritization in Failure Mode and Effect Analysis. IEEE Systems Journal, 1589-1600 (2017)

9. Bitar, S.D., Campos, C.P., Freitas, C.E.: (2016). Applying fuzzy logic to estimate the parameters of the length-weight relationship. Braz. J. Biol, 611-618 (2016)

10. Geramian, A., Mehregan, M.R., Garousi Mokhtarzadeh, N., Hemmati, M.: Fuzzy inference system application for failure analyzing in automobile industry. International Journal of Quality \& Reliability Management, 1493-1507 (2017)

11. Chacón, D.P., Lata, J.P., Medina, R.D. (2017). Health Index Assessment for Power Transformers with Thermal Upgraded Paper up to 230kV, Using Fuzzy Inference Part II: A Sensibility Analysis. In: International Caribbean Conference on Devices, Circuits and Systems (ICCDCS), 109-112 (2017) 